\title{
Does family always matter? Public genomes and their effect on relatives
}

\author{
Cinnamon S Bloss
}

Coinciding with the publication of the genome sequence of the HeLa cancer cell line last summer [1], US National Institutes of Health (NIH) administrators announced that they had been working closely with the family of Henrietta Lacks [2], the woman from whom the HeLa immortal cell line was derived, to address the family's concerns regarding privacy and informed consent. NIH officials noted that 'the full [HeLa] sequence data could potentially uncover unwanted information about people whose identity is widely known' - namely the family of Ms Lacks [2]. Such unwanted information could include disease risks, response to drugs, ancestral roots, and in some cases an individual's actual identity [3].

This article followed on the heels of another study published in March of this year that likewise presented a detailed account of the HeLa genome and included public posting of the data [4]. Days after publication of that article, a firestorm of commentary erupted on social media $[5,6]$ and formal news outlets, questioning the ethics of the study and public deposition of the data. The posting of the data also reportedly upset the Lacks family, with one family member quoted as saying, 'That is private family information...It shouldn't have been published without our consent' [7]. The NIH responded by entering into a much needed dialogue with the Lacks family to address these concerns. These events call attention to the issue of the impact of public release of an individual's identified data on biological family members, and the need for empirical research in this area to inform policy-making with regard to data sharing.

\section{Biological relatives and genome sequencing}

Given the ubiquity of HeLa cells in research and medicine and the fact that Ms Lacks herself never gave consent for the use of her tissues, the sequencing of the HeLa genome is clearly a unique case in terms of the

Correspondence: cbloss@scripps.edu

Scripps Genomic Medicine, Scripps Health, and Scripps Translational Science Institute, 3344 N, Torrey Pines Court, Suite 300, La Jolla, CA 92037, USA ethical issues raised and the need for a partnership with the Lacks family. However, this also raises a general issue about whether biological relatives have a 'right' to refuse, or consent, to another person's desire to undergo genome sequencing themselves, and to publicly release their identified data. The quote from Ms Lacks' family member implies that the family's concerns are not confined to the initial lack of consent from Ms Lacks. It appears that at least some members of the family also feel that the information is their 'private family information', the use of which should be subject to their consent.

This raises questions about individuals in other studies who have consented to have their genomes sequenced and agreed to put their identified data in the public domain. Should consent from those individuals' family members be considered as well? Currently at least 13 people are known to have undergone genome sequencing with deposition of their identified data in public databases, all with informed consent (an important difference relative to the case of Ms Lacks). Furthermore, this number is increasing.

Many of these individuals are among the 'first 10' participants in The Personal Genome Project (PGP), an innovative and open consent research initiative that enrolls volunteers who are willing to share their genome sequence and personal information (including identifying information) with both the research community and the general public [8]. The PGP does not require consent from family members, but does strongly suggest that potential participants discuss the possible implications of involvement in the project with biological relatives before enrolling. At the other end of the spectrum is the case of Jim Watson. Dr Watson, who is not a member of the PGP, was noted to have said that he purposely avoided consulting with his family prior to publishing his genome because 'they might have said no' [9]. Other non-PGP members who have publicly released their identified sequence data include Craig Venter and Stephen Quake. 
Several easily accessible books and websites suggest that, collectively, the group of 13 known individuals who have undergone sequencing with public deposition of identified data have at least twice as many living firstdegree relatives, some of whom are minors. First-degree relatives, by definition, share about half of their genome with the primary individual whose genome was sequenced. The extent to which these relatives may be affected by the publication of their family member's data is an important and interesting empirical question.

\section{A previous case}

The issue of protecting family members in survey and genetics research has come up before. In 2001, there was a reported dispute between the father of a young adult woman who was recruited to participate in a twin study, and Virginia Commonwealth University (VCU). Her father became aware of her participation and the fact that the investigators for the project had asked her to provide information about the health of her parents and other family members, including information he felt was sensitive and personal [10]. The father contacted the NIH's Office for Protection from Research Risks, which ruled that the VCU Institutional Review Board (IRB) should have considered the role of family members in the research, and whether or not consent should have been sought from family members. This, in turn, prompted a discussion about instances in which family members should be considered human research participants themselves (that is, if they are identifiable or if the information obtained about them from the primary participant constitutes private information) and whether there are circumstances in which informed consent from relatives can be waived [10].

Although research studies involving public deposition of identified genome sequences, including the HeLa genome sequence, would seem to warrant the need for consent from biological relatives according to the published criteria described above [10], it seems likely that this was not done in most, if not all, of the known cases. Furthermore, anecdotally, in the roughly 10 years I have spent doing family history, genetic and genomic research with human participants at a variety of institutions, there has never been an instance in which an IRB has requested that a study submitted for approval either include family member consent or include a list of reasons why informed consent for family members should be waived. Ultimately, it is unclear what the actual regulatory impact, if any, of the VCU case has been. What does seem clear, however, is the need for increased understanding of the impact of research like this on family members who, in some instances, may object to release of what they may feel is their private information, without their consent.

\section{The need for more data}

The partnership formed between the Lacks family and the NIH - and by extension the research community - is a positive step towards the responsible and ethical conduct of research involving HeLa cells, as well as research more generally. This is also, however, an opportunity to consider other instances in which individuals are making their identified genomes publicly available. Importantly, all publicly available identified genomes (perhaps also so-called 'de-identified' genomes [3]) have the potential to reveal health and other risks possessed by the primary individual's biological relatives, which could theoretically lead to harms encountered by such relatives. Quantifying the exact nature and extent of those harms and their likelihood is an important area for further research under the umbrella of ethical, legal and social issues in genomics. Although significant risks may theoretically be present, in reality they may be small or even negligible. Such risks may include genetic discrimination, or emotional or psychological harm stemming from family members learning of unexpected or unwanted personal genetic risk information that goes beyond family history information, of which they may or may not have already been aware. Empirical assessment of these possible phenomena would be a fruitful area for further study.

Mandating the need for consent from family members in genetic or other research studies seems premature, and actually implementing such a mandate would likely be logistically difficult. Perhaps even more importantly, such a mandate would limit autonomy of the primary research participant, one of the most closely held principles of research ethics. Furthermore, many would rightfully argue that such a policy would be an unnecessary hindrance for research more generally (not just genomic research, but any research in which family history information is obtained). Given the lessons learned from the case of Henrietta Lacks and her family, however, it is reasonable to consider that there is likely to be some degree of impact on biological relatives of individuals that choose to make their genomes public. Empirical research to understand the nature and extent of that impact could inform a data-driven approach for policy-making that is applicable to public data sharing in genomics more generally, rather than being limited to the specific case of HeLa cells.

\section{Abbreviations \\ IRB: Institutional Review Board; NIH: National Institutes of Health; PGP: The \\ Personal Genome Project; VCU: Virginia Commonwealth University.}

\section{Competing interests}

The author declares that she has no competing interests.

\section{Acknowledgements}

The author would like to thank Nicholas J Schork, Arthur R Derse, Eric J

Topol and Ben Daley for their comments on previous drafts of this

manuscript. The author would also like to thank Burcu Darst for her 
assistance with compiling references and manuscript formatting. In addition to affiliations with Scripps, CSB is also a student in the Bioethics Program at the Medical College of Wisconsin and would like to acknowledge program faculty and staff. This work was supported in part by an NIH/NCRR flagship Clinical and Translational Science Award grant (8UL1 TR001114-01) and the Scripps Genomic Medicine Division of Scripps Health. The funding organizations were not involved in the design or conduct of the study, the collection, management, analysis or interpretation of the data, the preparation, review or approval of the manuscript, or the decision to submit the manuscript for publication.

Published: 17 December 2013

\section{References}

1. Adey A, Burton JN, Kitzman JO, Hiatt JB, Lewis AP, Martin BK, Qiu R, Lee C, Shendure J: The haplotype-resolved genome and epigenome of the aneuploid HeLa cancer cell line. Nature 2013, 500:207-212.

2. Hudson KL, Collins FS: Family matters. Nature 2013, 500:141-142.

3. Gymrek M, McGuire AL, Golan D, Halperin E, Erlich Y: Identifying personal genomes by surname inference. Science 2013, 339:321-324.

4. Landry JJ, Pyl PT, Rausch T, Zichner T, Tekkedil MM, Stütz AM, Jauch A, Aiyar RS, Pau G, Delhomme N, Gagneur J, Korbel JO, Huber W, Steinmetz LM: The genomic and transcriptomic landscape of a HeLa cell line. G3 (Bethesda) 2013, 3:1213-1224.

5. Eisen M: The immortal consenting of HenriettaLacks. [http://www. michaeleisen.org/blog/?p=1341]

6. Eisen J: HeLa genome sequenced w/o obtaining permission/consent from family - some comments and background. [http://phylogenomics. blogspot.co.uk/2013/03/hela-genome-sequenced-wo-obtaining.html]

7. Skloot R: The immortal life of Henrietta Lacks, the sequel. New York Times 2013 [http://www.nytimes.com/2013/03/24/opinion/sunday/the-immortallife-of-henrietta-lacks-the-sequel.html?_r=0]

8. Ball MP, Thakuria JV, Zaranek AW, Clegg T, Rosenbaum AM, Wu X, Angrist M, Bhak J, Bobe J, Callow MJ, Cano C, Chou MF, Chung WK, Douglas SM Estep PW, Gore A, Hulick P, Labarga A, Lee J, Lunshof JE, Kim BC, Kim J, Li Z, Murray MF, Nilsen GB, Peters BA, Raman AM, Rienhoff HY, Robasky K, Wheeler MT, et al: A public resource facilitating clinical use of genomes. Proc Natl Acad Sci U S A 2012, 109:11920-11927.

9. Angrist M: Here is a Human Being. New York: Harper Collins; 2010.

10. Botkin J: Protecting the privacy of family members in survey and pedigree research. JAMA 2001, 285:207-211.

doi:10.1186/gm511

Cite this article as: Bloss: Does family always matter? Public genomes and their effect on relatives. Genome Medicine 2013 5:107. 